\title{
Remote sensing monitoring recent rapid increase of coal mining activity of an important energy base in northern China, a case study of Mu Us Sandy Land
}

\author{
N. Li ${ }^{a, b, c, *}$, C.Z. Yan ${ }^{a}$, J.L. Xie ${ }^{a}$ \\ a Key Laboratory of Desert and Desertification, Cold and Arid Regions Environmental and Engineering Research Institute, Chinese Academy of Sciences, No. \\ 260 West Donggang Road, Lanzhou, Gansu Province 730000, China \\ ${ }^{\mathrm{b}}$ Lanzhou Literature and Information Center of Chinese Academy of Sciences, No. 8 Tianshui Middle Road, Lanzhou, Gansu Province 730000, China \\ c University of Chinese Academy of Sciences, Beijing 100049, China
}

\section{A R T I C L E I N F O}

\section{Article history:}

Received 18 April 2014

Received in revised form

20 November 2014

Accepted 20 November 2014

Available online 23 December 2014

\section{Keywords:}

Mu Us Sandy Land

Mining region

Landsat

Land cover

Vegetation

\begin{abstract}
A B S T R A C T
Mu Us Sandy Land (MUSL) in northern China as a typical eco-fragile region contains approximately one-third of the Chinese coal reserves. The region has a long history of coal mining with prolonged human-induced activities that might accompany aeolian desertification development. Since China started implementing the western development policy in 2000, the mining activity has expanded rapidly in the MUSL region and impacted strongly the sustainable socioeconomic development. Up till now, only scattered information on these activities is available from specific studies. In this paper, based on the Landsat TM, ETM, and OLI images from 2000, 2005, 2010, and 2013, we monitor systematically the expansion of coal mining activity using the mining regions as an indicator and the changes of the land cover type due to the expansion of mining activity in the MUSL region. Based on these data, we developed a database of mining region by introducing a mining region classification system and use it to discuss the spatial and temporal evolution trends of mining activity. The obtained results provide evidences for managers to evaluate the execution of government planning and the effect of rapidly expanded mining activity on the local ecological environment.
\end{abstract}

(C) 2014 Elsevier B.V. All rights reserved.

\section{Introduction}

The Mu Us Sandy Land (MUSL) across Inner Mongolia Autonomous Region, Ningxia Hui Autonomous Region and Shaanxi Province, is an important ecological barrier in the northern China because the ecological environment in the MUSL region shows great sensitivity and vulnerability to natural and humanistic factors (Feng et al., 2013; Jinglu and Jianhua, 2012; Wu and Yang, 2013). There are approximate one-third of the Chinese coal reserves deposited in this region. The coal mining activities in the region began since 1954, and entered a stage of large-scale expansion after the initiation of the China's Western Development Policy (CWDP) in 2000 (Lai, 2002). With implementing the CWDP, the MUSL has become one of the fastest-growing districts of coal mining resources in China. It is no question that the coal mining expansion

\footnotetext{
* Corresponding author at: Lanzhou Literature and Information Center of Chinese Academy of Sciences, No. 8 Tianshui Middle Road, Lanzhou, Gansu Province 730000 , China. Tel.: +86 09318270744; fax: +86 09318270744 .

E-mail address: lina@llas.ac.cn (N. Li).
}

contributes significantly to the local GDP, but also causes environmental degradation and loss of ecosystem equilibrium due to the destruction of original land cover types and ecological processes. The conflict between the mining activities and the environmental protection in the region has intensified over recent years. During the large-scale expansion stage, local governments have constituted many planning to guide the regional energy development and ecological environment construction. Thus, studying the evolution of mining activity and the changes of the land cover type resulting from the mining expansion since the initiation of CWDP is vital for the managers to understand comprehensively the mining expansion process and to identify the effects of rapidly expanded mining activity on the ecological environment in the MUSL region.

Remote sensing is an effective tool for monitoring and estimating the spatially and temporally explicit information in a large region (Archer, 2004; Chen et al., 2012; Tadesse et al., 2005; Zhang et al., 2012). Satellite images frequently acquired over long periods provide unique opportunities to study the long-term land cover changes. In particular, multispectral satellite imagery, such as that provided by Landsat TM, ETM, and OLI images, is a precious resource for long-term analyses of surface processes (Wang et al., 2012). 


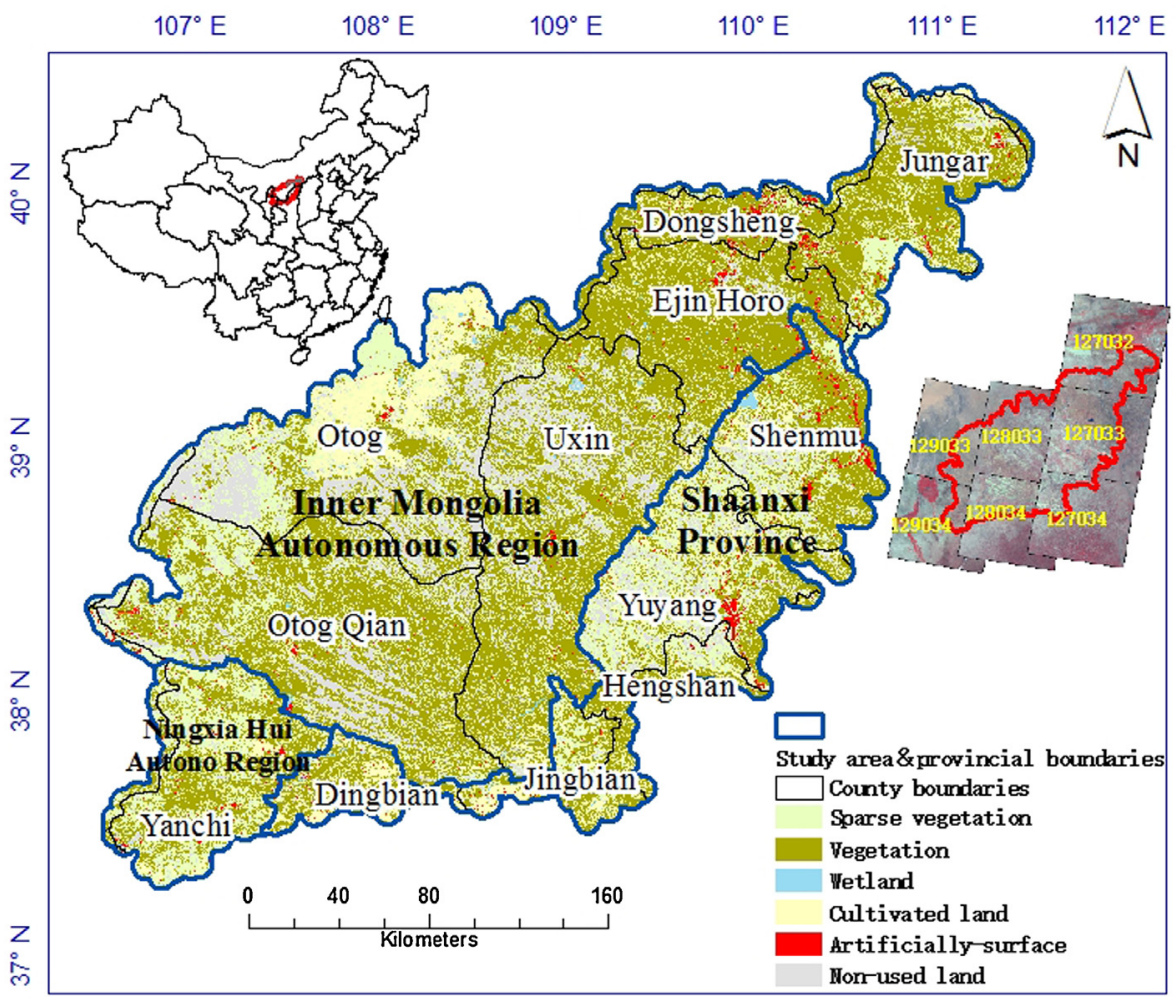

Fig. 1. Location and land cover/use (2010) of the study area.

In the past decade, many efforts have been devoted to study the ecological environment problems due to aeolian desertification in the MUSL region using remote sensing technique (Luk, 1983; Runnström, 2003; Yan et al., 2013; Zha et al., 2008). For example, the degradation of the dry semiarid ecosystems in the MUSL region between 1978 and 1996 was explored by monitoring both changes in grassland biomass production and reclamation activities (Runnström, 2003). Subsequently, the land cover changes of Yulin City located in the eastern part of MUSL region between 1985 and 2000 were quantified and the major factors responsible for these changes were identified as the change in the government policy on preserving the environment, continued growth in coal mining activity, and urbanization (Zha et al., 2008). Recently, the aboveground biomass between 1988 and 2007 was also estimated using Landsat spectral derived vegetation indices (Yan et al., 2013). However, to our knowledge, all these studies have concentrated on the land cover changes in general; up to now, no studies have focused on the type of land cover change due to the disturbances of specific human activities such as the large-scale expansion of coal mining in the MUSL region during the periods of CWDP implementation.

In this paper, we obtain Landsat TM/ETM/OLI data from four dates $(2000,2005,2010$, and 2013) covering the entire period of the implementation of the CWDP. Using the data we discuss the temporal and spatial evolution of the mining activity and of the land cover type resulting from the expansion of mining activity in the MUSL region during the periods between these years.

\section{Study area}

The MUSL region in northern China lies on the agro-pastoral transition zone, and the land use mainly includes agriculture, animal husbandry, industry, and mine. The ecological transition indicates a fragile and complex ecosystem in the region, i.e. once the regional ecosystem is destroyed it will be difficult to recover in time. Based on the moving dunes, we obtained $5 \mathrm{~km}$ buffer zone in the MUSL region and define this boundary as our study area covering an area of approximately $72,000 \mathrm{~km}^{2}\left(37^{\circ} 27^{\prime}-40^{\circ} 22^{\prime} \mathrm{N}\right.$, $106^{\circ} 20^{\prime}-111^{\circ} 30^{\prime} \mathrm{E}$ ). The location and the land cover/use of study area are shown in Fig. 1, where the Fig. 1 comes from Landsat TM images for 2010 used in the present study (see Section 3). It includes all of the Ejin Horo and Uxin, the southwest part of Jungar Banner, and eastern parts of Otog and Otog Qian (located in southern Inner Mongolia Autonomous Region); the northeast part of Yanchi (located in eastern Ningxia Hui Autonomous Region); the northwest part of the sandy area in Yuyang district and Shenmu county, the northern part of the sandy area in Dingbian, Jingbian, and Hengshan (located in northern Shaanxi Province). The elevation ranges from 950 to $1600 \mathrm{~m}$, and its climate type varies from middle temperate zone to warm temperate zone. The annual mean temperature is $6.0-8.5^{\circ} \mathrm{C}$, and the mean annual precipitation varies in a northwest to southeast direction from 250 to $440 \mathrm{~mm}$. Semimobile sand dune and semi-fixed sand dune occupied the majority of MUSL, fixed sand dune widely distributed in the study region (Yan et al., 2005). Land cover types are complex, and staggered distributions of different types are very common. In such a transition region containing about one-third of the Chinese coal reserves, the increasing mining activities will strongly impact the sustainable socioeconomic development.

\section{Materials and methods}

\subsection{Data sources}

The remote-sensing data used to derive the temporal and spatial evolution of the mining activity and of the land cover type resulting from the expansion of mining activity comprised Landsat TM, ETM, and OLI images with a $30 \mathrm{~m}$ spatial resolution. We acquired ETM images for the 2000 data, TM images for the 2005/2010, and OLI images for the 2013 data. The details of satellite data used are given in Table 1. All images were obtained from May to October in 
Table 1

Landsat satellite data sets for monitoring of coal mining in MUSL.

\begin{tabular}{ll}
\hline Path/row & Date of acquisition \\
\hline $127 / 032$ & $20130711 / 20090630 / 20060910 / 20000731$ \\
$127 / 033$ & $20130812 / 20090630 / 20060910 / 20000731$ \\
$127 / 034$ & $20130812 / 20100617 / 20060910 / 20000605$ \\
$128 / 033$ & $20130803 / 20100827 / 20061019 / 20000503$ \\
$128 / 034$ & $20130803 / 20100710 / 20061019 / 19990922$ \\
$129 / 033$ & $20130607 / 20100717 / 20040817 / 20000830$ \\
$129 / 034$ & $20130607 / 20101717 / 20060807 / 20000830$ \\
\hline
\end{tabular}

study years, when vegetation in the study area typically reaches its maximum extent during the region's growing season. As it was difficult to acquire cloud-free images that covered the whole study area within a given year due to its large area, some images from 1999, 2004/2006 and 2009 were chosen to replace unsuitable (bad track and cloudy) images from 2000, 2005, and 2010, respectively. During each time period, 7 images were obtained to cover the whole study area (see the Fig. 1).

\subsection{Classification system}

In this study, a classification system for the land use/cover in the MUSL region have been introduced according to a modified version published in our previous work (Song et al., 2009). Six land use/cover types, namely vegetation, sparse vegetation, wetland, cultivated land, artificially surface, and non-used land, were defined by detailed consideration of the imaging spectral characteristics and indices are shown in Table 2, where the parameter of vegetation cover ratio $\left(C_{r}\right)$ is defined as the percentage or fraction of occupation of vegetation canopy in a given ground area in vertical projection. Noteworthy is that we also introduce a specific second-level land use/cover type named as mining region to indicate the mining activity and assigned in the artificially surface type. The mining region is defined as the land use/cover of mining, including the mine-pit area, overburden-dump area, production-management area, and life-service area. Furthermore, we proposed the size of mining region as a main criterion to classify the mining region scale into four degrees: small $\left(<1.0 \mathrm{~km}^{2}\right)$, medium $\left(1.0-5.0 \mathrm{~km}^{2}\right)$, large $\left(5-10.0 \mathrm{~km}^{2}\right)$, and especially large $\left(>10.0 \mathrm{~km}^{2}\right)$. To some extent, the proportion of small mining regions in the total mining regions can show the fragmentation degree of mining activity distributions.

\subsection{Image processing and interpretation}

We used 7 Landsat images from each year to develop a database of mining region at a spatial scale of $1: 100,000$ by means of visual interpretation and digitization using version 7.01 of the Intergraph MGE (Modular GIS Environment) software (Intergraph, Huntsville, $\mathrm{AL}$ ). Before the interpretation, according to the characteristics of different bands and statistical characteristics, bands 4,3 , and 2 were used to create false-color composite RGB images for the

Table 2

The land use/cover type classification system used in this study.

\begin{tabular}{|c|c|}
\hline Type & Description \\
\hline Vegetation & $\begin{array}{l}\text { Trees, shrubs, and other forested lands, grassland, } \\
\text { cover ratio }\left(C_{r}\right)>20 \%\end{array}$ \\
\hline Wetland & River, lake, reservoir or pond, beach, bottomland \\
\hline Cultivated land & Dry farmland, irrigable land \\
\hline Artificially surface & $\begin{array}{l}\text { Urban area, rural residential area, mining region, other } \\
\text { built-up area }\end{array}$ \\
\hline Sparse vegetation & $\begin{array}{l}\text { The same secondary types with vegetation, } \\
4 \%<C_{r}<20 \%\end{array}$ \\
\hline Non-used land & $\begin{array}{l}\text { Sandy land, saline land, marsh, bare land, bare rock, } \\
\text { other unused land }\end{array}$ \\
\hline
\end{tabular}

2000/2005/2010; bands 6, 5, 4 were used to create color infrared composite images for the other images (Landset- 8 in 2013). Then, a graphical indicator named as normalized deviation vegetation index (NDVI) was used to enhance the interpretability of the remote sensing images and to quantify the vegetation $C_{r}$ based on a dimidiate pixel model (Wu et al., 2004). Using the Image Analyst function of the Module GIS Environment (MGE) software, we georeferenced and orthorectified the images using 50-60 Ground Control Points (GCPs) derived from a 1:100,000 topographic map created in 1980 by the Chinese State Bureau of Surveying and Mapping. Furthermore, Landsat images were accurately positioned by field-survey GPS data. The mean location error was less than 1 pixel (i.e., $\backslash 30 \mathrm{~m}$ ). The 2005 images to the 2000 images were then matched by means of an image-to-image matching method. During image-matching process, 40-50 GCPs in 2005 and 2000 were randomly selected to cover most of the area represented by the two sets of images (Song et al., 2012). The same method was used to process the 2010 images and the 2013 images.

Visual interpretation was based on image characteristics such as size, shape, tone, texture, site association, shadow, and pattern. For example, we interpreted the mining region according to the patch features. (1) mining-pit area: black tone, medium to smooth texture having linear to curvilinear pattern and irregular shape; (2) overburden-dump area: white to light blue tone, coarse to medium texture having contiguous pattern and irregular outer shape; (3) production-management area and life-service area: gray tone and regular outer shape, located near the mine pit. During interpretation, the following mapping principles were adopted: (1) the minimum mapping patch was $5 * 5$ pixels; (2) the deviation of delineating locations was less than 1 pixel on the screen; and (3) the overall accuracy of classification was greater than $95 \%$, which is defined as the proportion of pixels whose class labels agree with the ground reference. Other land cover types were interpreted using the similar method with previous works (Song et al., 2009).

Once the digital map of the land coverage in 2000 was complete, the patches were copied and the segments that needed modification were changed based on the 2005, 2010, and 2013 images; the patches in the 2005 were updated (by adding, deleting, or modifying lines) and generated the land cover data compared with the 2000 land coverage map in 2005; similarly, the land cover data in 2010 and 2013 were acquired used the same methods.

After the interpretations were finished, the digitization of thematic maps was completed and the digital thematic maps were given to quality inspectors who were experts in the studies and the classification. These inspectors assessed the accuracy based on confusion matrix. If the accuracy did not satisfy the mapping standards, the maps were reinterpreted and rechecked until the mapping accuracy reached the mapping principles. Some images acquired from the Google earth, which have characteristics and spatial resolution similar to those of the Landsat images, were also used as ancillary materials to confirm the results of our interpretation.

\section{Results}

Analyzing the temporal and spatial distribution of mining region can help to reveal the change trends of mining activity and the relationships between the resulting changes and land degradation. The evolution of the mining region in MUSL during the period of 2000-2013 was quantified by the difference between classified images from 2000, 2005, 2010, and 2013 (Fig. 2). It was found that most of the mining regions are distributed in the northeastern MUSL region (Dongsheng District, Jungar Banner and Shenmu County of Inner Mongolia Autonomous Region). Just a few mining regions are distributed in the other parts of MUSL region. The monitored results of mining regions as a database were summarized in Table 3. 

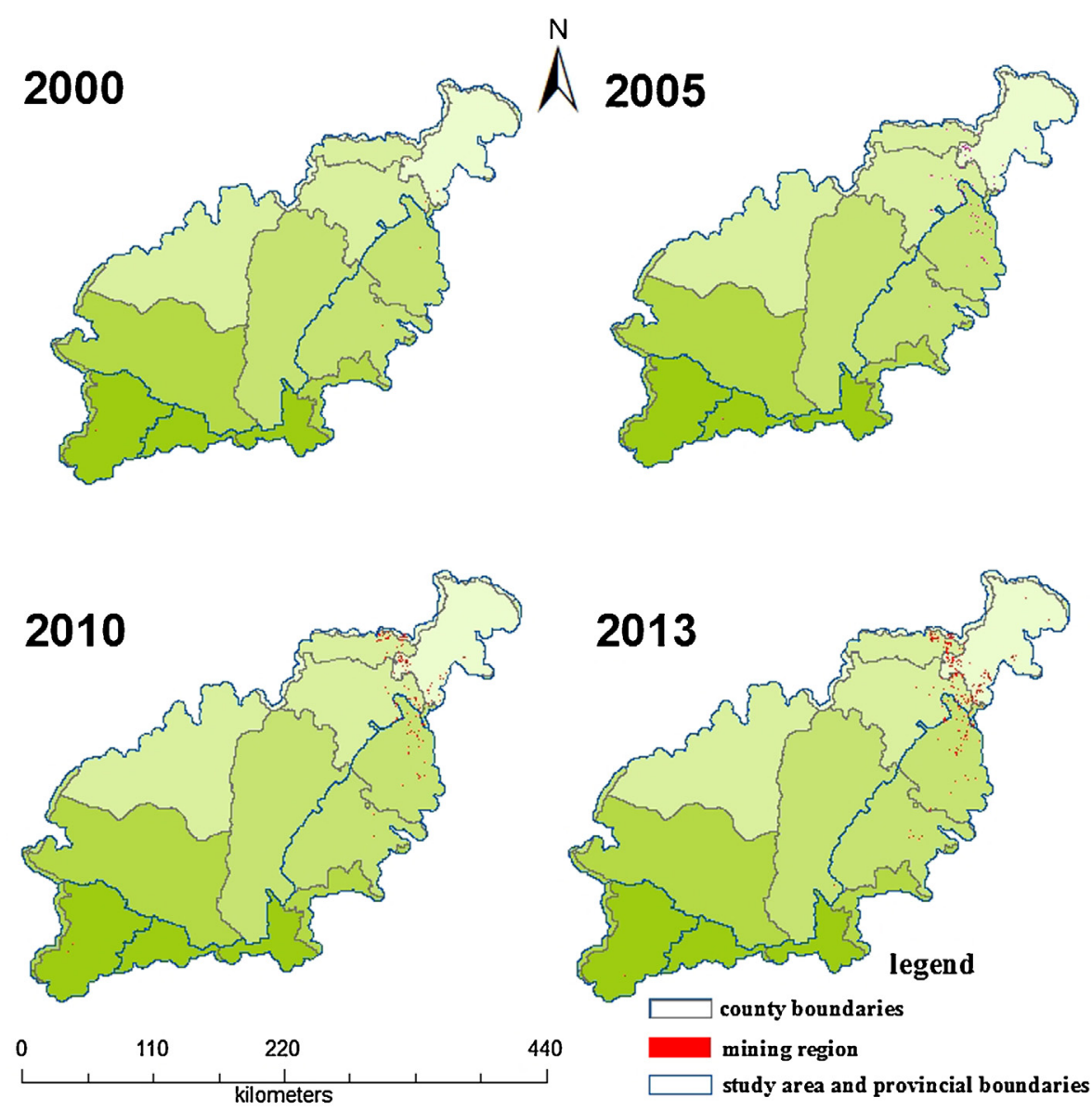

Fig. 2. Spatial and temporal distribution of mining region in the study area.

In 2000, the total sizes of the mining regions, detected from Landsat images, occupied $22.7 \mathrm{~km}^{2}$ (approximate $0.03 \%$ exists within the total study area). The large and especially large mining regions were absent in the date. The small and medium mining regions accounted for 20 and $2.7 \mathrm{~km}^{2}$, respectively, accounting for $88.1 \%$ and $11.9 \%$ of the total sizes of the mining regions (Table 1 ). After the initiation of CWDP, the mining activity has changed significantly. The mining regions were expanded by $60.5 \mathrm{~km}^{2}$ from 2000 to 2005 , representing a $267 \%$ increase in the total sizes and an average rate of increase of $12.1 \mathrm{~km}^{2}$ per year. In 2005 , although the large and especially large mining regions were still absent, the small mining regions were decreased to $80.6 \%$ of the total areas from previous $88.1 \%$. The subsequent trends in change of mining regions were steady. For example, the mining regions were expanded by $94.8 \mathrm{~km}^{2}$ from 2005 to 2010 representing an average rate of increase of $19.0 \mathrm{~km}^{2}$ per year and the ratio of small mining regions were decreased to $48.9 \%$; the mining regions were expanded by $152.6 \mathrm{~km}^{2}$ from 2010 to 2013 representing an average rate of increase of $50.9 \mathrm{~km}^{2}$ per year and the ratio of small mining regions were decreased to $30.5 \%$. Noteworthy is that the large and especially large mining regions appear since 2010 and they accounted for 72.6 and $48.4 \mathrm{~km}^{2}$ in 2013 , respectively, accounting for $22.0 \%$ and $14.6 \%$ of the total areas of the mining regions. From these results one can see that the total sizes of the mining regions in the study area are rapidly increasing with a progressive growth rate and the fragmentation degree of mining region distribution has an obvious decrease during the past 13 years.

According to the administrative division (Fig. 1), the MUSL region was spatially delineated into three separate parts which belong to Inner Mongolia Autonomous Region, Shaanxi Province, and Ningxia Hui Autonomous Region, respectively. Here we only presented the differential distributions of the mining regions belonging to Inner Mongolia Autonomous Region and Shaanxi Province because more than $96 \%$ of the mining regions are located in the two administrative regions. The differential databases of mining regions associated with Inner Mongolia Autonomous Region

Table 3

Changes in the size of mining region from 2000 to 2013 in the MUSL.

\begin{tabular}{|c|c|c|c|c|c|c|c|c|c|c|}
\hline \multirow[t]{3}{*}{ Year } & \multicolumn{8}{|c|}{ Mining region scale } & \multicolumn{2}{|c|}{ Total mining region } \\
\hline & \multicolumn{2}{|c|}{ Especially large } & \multicolumn{2}{|l|}{ Large } & \multicolumn{2}{|l|}{ Medium } & \multicolumn{2}{|l|}{ Small } & \multirow[b]{2}{*}{ Size $\left(\mathrm{km}^{2}\right)$} & \multirow[b]{2}{*}{$\begin{array}{l}\% \text { of study } \\
\text { region }\end{array}$} \\
\hline & Size $\left(\mathrm{km}^{2}\right)$ & $\begin{array}{l}\% \text { of total } \\
\text { mining region }\end{array}$ & Size $\left(\mathrm{km}^{2}\right)$ & $\begin{array}{l}\% \text { of total } \\
\text { mining region }\end{array}$ & Size $\left(\mathrm{km}^{2}\right)$ & $\begin{array}{l}\% \text { of total } \\
\text { mining region }\end{array}$ & Size $\left(\mathrm{km}^{2}\right)$ & $\begin{array}{l}\% \text { of total } \\
\text { mining region }\end{array}$ & & \\
\hline 2000 & & & & & 2.7 & 11.9 & 20.0 & 88.1 & 22.7 & 0.03 \\
\hline 2005 & & & & & 16.2 & 19.4 & 67.0 & 80.6 & 83.2 & 0.11 \\
\hline 2010 & 11.9 & 6.7 & 13.5 & 7.6 & 65.6 & 36.8 & 87.0 & 48.9 & 178 & 0.25 \\
\hline 2013 & 48.4 & 14.6 & 72.6 & 22.0 & 108.7 & 32.9 & 100.9 & 30.5 & 330.6 & 0.46 \\
\hline
\end{tabular}


Table 4

Changes in the size of mining region belong to Inner Mongolia Autonomous Region from 2000 to 2013.

\begin{tabular}{|c|c|c|c|c|c|c|c|c|c|}
\hline \multirow[t]{3}{*}{ Years } & \multicolumn{8}{|c|}{ Mining region scale } & \multirow[t]{3}{*}{ Total size $\left(\mathrm{km}^{2}\right)$} \\
\hline & \multicolumn{2}{|c|}{ Especially large } & \multicolumn{2}{|l|}{ Large } & \multicolumn{2}{|l|}{ Medium } & \multicolumn{2}{|l|}{ Small } & \\
\hline & Size $\left(\mathrm{km}^{2}\right)$ & $\%$ of total size & Size $\left(\mathrm{km}^{2}\right)$ & $\%$ of total size & Size $\left(\mathrm{km}^{2}\right)$ & $\%$ of total size & Size $\left(\mathrm{km}^{2}\right)$ & $\%$ of total size & \\
\hline 2000 & & & & & 1.2 & 9.6 & 11.0 & 90.4 & 12.2 \\
\hline 2005 & & & & & 12.73 & 22.9 & 42.8 & 77.1 & 55.5 \\
\hline 2010 & 11.9 & 8.8 & 13.5 & 10.0 & 51.901 & 38.4 & 58.0 & 42.8 & 135.3 \\
\hline 2013 & 48.4 & 19.4 & 58.2 & 23.3 & 86.351 & 34.5 & 57.1 & 22.8 & 250.1 \\
\hline
\end{tabular}

Table 5

Changes in the size of mining region belong to Shaanxi Province from 2000 to 2013.

\begin{tabular}{|c|c|c|c|c|c|c|c|c|c|}
\hline \multirow[t]{3}{*}{ Years } & \multicolumn{8}{|c|}{ Mining region scale } & \multirow[t]{3}{*}{ Total size $\left(\mathrm{km}^{2}\right)$} \\
\hline & \multicolumn{2}{|c|}{ Especially large } & \multicolumn{2}{|l|}{ Large } & \multicolumn{2}{|l|}{ Medium } & \multicolumn{2}{|l|}{ Small } & \\
\hline & Size $\left(\mathrm{km}^{2}\right)$ & $\%$ of total size & Size $\left(\mathrm{km}^{2}\right)$ & $\%$ of total size & Size $\left(\mathrm{km}^{2}\right)$ & $\%$ of total size & Size $\left(\mathrm{km}^{2}\right)$ & $\%$ of total size & \\
\hline 2000 & & & & & 1.5 & 15.6 & 8.3 & 84.4 & 9.8 \\
\hline 2005 & & & & & 3.2 & 12.0 & 23.7 & 88.1 & 26.9 \\
\hline 2010 & & & & & 11.8 & 28.9 & 29.0 & 71.2 & 40.8 \\
\hline 2013 & & & 7.6 & 9.6 & 25.7 & 32.3 & 46.2 & 58.1 & 79.6 \\
\hline
\end{tabular}

Table 6

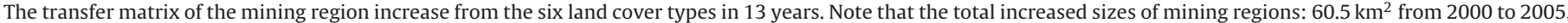
$94.8 \mathrm{~km}^{2}$ from 2005 to 2010, and $152.6 \mathrm{~km}^{2}$ from 2010 to 2013.

\begin{tabular}{|c|c|c|c|c|c|c|}
\hline \multirow[t]{2}{*}{ Type of land cover } & \multicolumn{2}{|l|}{ 2000-2005 } & \multicolumn{2}{|l|}{ 2005-2010 } & \multicolumn{2}{|l|}{ 2010-2013 } \\
\hline & Size $\left(\mathrm{km}^{2}\right)$ & Rate (\%) & Size $\left(\mathrm{km}^{2}\right)$ & Rate (\%) & Size $\left(\mathrm{km}^{2}\right)$ & Rate (\%) \\
\hline Vegetation & 31.88 & 52.90 & 40.93 & 43.31 & 143.70 & 93.53 \\
\hline Wetland & 0.33 & 0.55 & 0.02 & 0.03 & 0.66 & 0.43 \\
\hline Cultivated land & 2.82 & 4.68 & 3.74 & 3.99 & 4.34 & 2.82 \\
\hline Artificially surface & 7.92 & 13.14 & 7.31 & 7.79 & 23.00 & 14.97 \\
\hline Sparse vegetation & 9.71 & 16.11 & 3.15 & 3.36 & 73.69 & 47.96 \\
\hline Non-used land & 16.26 & 26.99 & 85.20 & 90.79 & 12.85 & 8.36 \\
\hline Total & 68.93 & 114.37 & 140.35 & 149.57 & 258.24 & 168.07 \\
\hline
\end{tabular}

and Shaanxi Province are shown in the Tables 4 and 5, respectively. For the two cases, during the period between 2000 and 2013, the total sizes of mining regions are all rapidly increasing from 12.2 to $250.1 \mathrm{~km}^{2}$ in the former and from 9.8 to $79.6 \mathrm{~km}^{2}$ in the latter; the fragmentation degrees of mining region distributions are all obvious decreasing because the ratio of small mining regions has a general decrease from $90.4 \%$ to $22.8 \%$ in the former and from $84.4 \%$ to $58.1 \%$ in the latter. It was also found that most of the large and all the especially large mining regions located in the MUSL region are mainly distributed in Inner Mongolia Autonomous Region. The results suggest that the expansion of mining activity in Inner Mongolia Autonomous Region is faster and has a more successful regularization for the mining region distribution than in Shaanxi Province.

In an eco-fragile area, different types of land cover have different ability to protect the regional ecological equilibrium and to resist the external disturbance. Thus, it is significant to monitor the land cover changes caused by expansion of mining activity. Table 6 presented the main types of land cover transforming to mining region in the MUSL region during the large-scale exploration stage. Here, we define a ratio, equal to the size of each land use/cover type occupied by expansion of mining activity divided by the total increased sizes of mining regions in corresponding period, as a quantitative parameter shown in Table 6 . When the expansion of mining activity is ideally characterized by expanding an old smaller mine, the sum of the six ratios (total ratio) is equal to unit; when the expansion of mining activity is ideally characterized by exploiting a new larger mine and closing an old smaller mine, the ratio is larger than unit.

Returning now the present results shown Table 6, one can see that the six types collectively contributed the transformation during the entire study period. The largest contribution in the transformation types was found to be the vegetation type from 2000 to 2005 (31.88 $\left.\mathrm{km}^{2}, 52.90 \%\right)$ and from 2010 to $2013\left(143.70 \mathrm{~km}^{2}\right.$, 93.53\%), and to be the non-used land type from 2005 to 2010 $\left(85.2 \mathrm{~km}^{2}, 90.8 \%\right)$. The sparse vegetation type $\left(73.7 \mathrm{~km}^{2}, 47.96 \%\right)$ also plays an important role in the latest three years. Actually, one can also see that the sum of the six ratios (total ratio) is always larger than unit and have a rapid increase in the last 13 years. In other words, the total decreased sizes of the six types are always larger than the total increased sizes of mining regions and their difference has increasingly widened. The results indicate that, with times going, the expansion of mining activity in the last 13 years is mainly associated with the closure of old smaller mines and the exploitation of new larger mines. Especially to deserve to be mentioned, the restoration for the closed mining regions has not been considered in the work.

\section{Discussion}

In MUSL regions, the general expansion of mining activities during the past 13 years should be attributed to the CWDP that is a planning adopted for the western region of China covering the entire MUSL region clarified in 1999 and initiated in 2000. The economic developments and the environmental protection are two key strategies components of CWDP. The combined effect of the two components will cause a reasonable distribution of mining activity in the study region, needing at least great efforts to develop the large-scaled mines and to limit the development of small mines. Our results show that, with implementing the CWDP, the ratio of small mining regions keeps a sharp decrease and large and 
Table 7

Relevant regulations and policies for mining development and the environmental protection in Inner Mongolia Autonomous Region and Shaanxi Province (Mongolia, 2011; Shaanxi, 2012).

\begin{tabular}{l}
\hline Local planing \\
\hline The Inner Mongolia \\
Autonomous Region
\end{tabular}

(2001-2010)

Shaanxi Province (2001-2010)
Reference to exploitation

To 2005, requiring that two important energy supply bases are constructed, Dongsheng steam coal export base and Shenhua energy;

Ten coal mine such as Dongsheng coal mine and Junggar coal mine (located in MUSL) are regularized; existing mines are restructured for achieving suitable scale and distribution; the qualification and access conditions of new mine enterprise are strict controlled for reversing the current status of irrational distribution of coal mines To 2010, requiring that scale operation and intensive production are basically achieved; the coordinate mechanism of mining development and the environment protection is established. Exploitation of superior quality coal is encouraged in northern Shaanxi. Encouraging the construction of large and medium-sized mines along the railway or road in Yulin-Shenmu. Designating standards of mine production, limiting and closing small mines (annual output of less than 300 thousand tons)
$330.6 \mathrm{~km}^{2}$; the small mining regions $\left(<1 \mathrm{~km}^{2}\right)$ were monotonically decrease to $30.5 \%$ of the total sizes of mining regions from previous 88.1\%; the large $\left(5-10 \mathrm{~km}^{2}\right)$ and especially large $\left(>10 \mathrm{~km}^{2}\right)$ mining regions were observed for the first time in 2010 and their ratio of the total sizes of mining regions increased to $37 \%$ in 2013 . The results indicate that, although the mining activity has expanded rapidly, the distribution of mining activity in the study region is tending toward rationality.

The analysis for land use/cover changes caused by expansion of mining regions showed that the vegetation and sparse vegetation, as the crucial original land cover types for a typical eco-fragile region, were two main dominant types for attributed to change of mining regions during the study period. The monitored results provide evidences for managers to evaluate the effects of mining activity in the typical eco-fragile region to constitute new planning for more sustainable development of the mining activity.

Despite our promising results, there are limitations on the accuracy of mining region monitoring using remote sensing data. In particular, the main constraints are limitations on our ability to acquire high quality images simultaneously for the whole region being monitored and a lack of experienced visual interpreters. Nonetheless, we believe that monitoring of mining activity will become more efficient and objective using the data acquired by other remote sensors, such as China's CBERS with a higher space resolution (about $19.5 \mathrm{~m}$ ) and $\mathrm{HJ}-1$ satellites with a shorter revisit period (about four days), and by developing a more effective quantitative method (i.e., an appropriate computer algorithm) for monitoring mining regions using the data from these satellites.

\section{Acknowledgements}

suggesting that the distribution of mining activity tends to be more reasonable in the implementation period of CWDP.

To evaluate the execution of government planning, in Table 7 we listed the main regulations and policies referring to mining developments and the environmental protection, which were constituted by the local governments of Inner Mongolia Autonomous Region and Shaanxi province according to the key strategies of CWDP initiation. Better execution of government planning in Inner Mongolia Autonomous Region was obtained because of its more rational distribution of mining activity, i.e. the development of small mining regions were more effective limited and the development of large-scaled mining regions were more effective promoted.

Although the partial rationality for mining activity in the study region has been confirmed from the aspect of size distribution of mining regions, one should pay attention to the fact that some crucial original land cover types such as vegetation and sparse vegetation have been spoiled severely by the extension of mining activity. In the eco-fragile region, when the vital protecting vegetation cover is reduced, wind erosion accelerates and mobile sand dunes will be formed, and further aeolian desertification will develop. Sand can be transported long distances by severe sandstorms causing damage far away from its departure. Only from the present data, the extent of the damage to ecological processes due to the expansion of mining activity is not well estimated. But, it will be important to remind local managers to enhance the execution of existing policy and to constitute new policy for more sustainable socioeconomic development.

\section{Conclusions}

Mining activity monitoring in the MUSL region provides an example of the use of remote sensing and GIS to develop a database of mining region covering the period of CWDP implementation from 2000 to 2013 . Our analysis showed that the mining activity in the region has been rapidly developing during the past 13 years. The total sizes of mining regions monotonically increased from 22.7 to
This research was supported by the Key Program of the Chinese Academy of Sciences (KZZD-EW-04-04) and National Natural Science Foundation of China (General Program: 41171400).

\section{References}

Archer ERM. Beyond the "climate versus grazing" impasse: using remote sensing to investigate the effects of grazing system choice on vegetation cover in the eastern Karoo. J Arid Environ 2004;57(3):381-408.

Chen YY, Wang Y, Li DL, Wu X. A monitoring system based on environment indicato technology for land rehabilitation in coal mine dump areas. Intell Autom Soft Comput 2012;18(5):547-56.

Feng W, Zhang YQ, Wu B, Zha TS, Jia X, Qin SG, et al. Influence of disturbance on soil respiration in biologically crusted soil during the dry season. Sci World J 2013;2013:408560

Jinglu P, Jianhua Z. Study on effects of household demography on land use in environmental degradation area: Mu Us Desert in northwestern China as an example northwest population. Northwest Popul J 2012;33(2):6-10.

Lai HH. China's western development program: its rationale, implementation, and prospects. Mod China 2002;28(4):432-66

Luk SH. Recent trends of desertification in the Maowusu desert, China. Environ Conserv 1983;10(3):213-24.

Ministry of Land and Resources of Inner Mongolia. Mineral resources planning of inner Mongolia (2001-2010); 2011 http://www.mlr.gov.cn/ kczygl/kcgh/201111/t20111103_1020985.htm

Ministry of Land and Resources of the Shaanxi Province. Mineral resources planning of Shaanxi province, 2001-2010 (abstract); 2012 http://www. mlr.gov.cn/kczygl/kcgh/201207/t20120720_1123087.htm

Runnström M. Rangeland development of the Mu Us Sandy Land in semiarid China: an analysis using Landsat and NOAA remote sensing data. Land Degrad Dev 2003:14(2):189-202.

Song X, Yang GX, Yan CZ, Duan HC, Liu GY, Zhu YL. Driving forces behind land use and cover change in the Qinghai-Tibetan Plateau: a case study of the source region of the Yellow River, Qinghai Province, China. Environ Earth Sci 2009;59(4):793-801.

Song X, Yan CZ, Xie JL, Li S. Assessment of changes in the area of the water conservation forest in the Qilian Mountains of China's Gansu province, and the effects on water conservation. Environ Earth Sci 2012:66(8):2441-8.

Tadesse T, Brown JF, Hayes MJ. A new approach for predicting drought-related vegetation stress: integrating satellite, climate, and biophysical data over the US central plains. ISPRS J Photogramm 2005;59(4):244-53. 
Wang T, Yan CZ, Song X, Xie JL. Monitoring recent trends in the area of aeolian desertified land using Landsat images in China's Xinjiang region. ISPRS J Photogramm 2012;68:184-90

Wu B, Yang H. Spatial patterns and natural recruitment of native shrubs in a semiarid sandy land. PLOS ONE 2013;8(3):e58331.

Wu BF, Li MM, Yan CZ, Zhou WF. Developing method of vegetation fraction estimation by remote sensing for soil loss equation: a case in the Upper Basin of Miyun Reservoir. In: 24th IEEE international geoscience and remote sensing symposium, Vols. 1-7: science for society: exploring and managing a changing planet; 2004 September 20-24, Anchorage, AK. New York: IEEE; 2004. p. $4352-5$.
Yan CZ, Wang T, Han ZW. Using MODIS data to assess land desertification in Ordos Plateau - Mu Us Sandy Land case study. In: 25th IEEE international geoscience and remote sensing symposium. Vols. 1-8: proceedings; 2005 July 25-29, Seoul, South Korea. New York: IEEE; 2005. p. 2373-5.

Yan F, Wu B, Wang Y. Estimating aboveground biomass in Mu Us Sandy Land using Landsat spectral derived vegetation indices over the past 30 years. J Arid Land 2013:5(4):521-30.

Zha Y, Liu Y, Deng X. A landscape approach to quantifying land cover changes in Yulin, Northwest China. Environ Monit Assess 2008;138(1-3):139-47.

Zhang B, Wu D, Zhang L, Jiao QJ, Li QT. Application of hyperspectral remote sensing for environment monitoring in mining areas. Environ Earth Sci 2012;65(3):649-58. 